\title{
Analysis of the rRNA methylation complex components in pediatric B-cell precursor acute lymphoblastic leukemia: A pilot study
}

\author{
Marek Ussowicz, ${ }^{1, B-F}$, Virginie Marce ${ }^{2, B, D-F}$, Flora Nguyen Van Long ${ }^{2, B, C, E}$, \\ Bernarda Kazanowska ${ }^{1, B, E, F}$, Jean-Jacques Diaz ${ }^{2, A, E, F}$, Dariusz Wołowiec ${ }^{3, A, E, F}$ \\ ${ }^{1}$ Department of Pediatric Bone Marrow Transplantation, Oncology and Hematology, Wroclaw Medical University, Poland \\ 2 The Université Claude Bernard Lyon 1, Centre Léon Bérard, Centre de Recherche en Cancérologie de Lyon, France \\ ${ }^{3}$ Department and Clinic of Hematology, Blood Neoplasms and Bone Marrow Transplantation, Wroclaw Medical University, Poland \\ A - research concept and design; B - collection and/or assembly of data; C - data analysis and interpretation; \\ $D$ - writing the article; $E$ - critical revision of the article; $F$ - final approval of the article
}

\begin{abstract}
Address for correspondence
Marek Ussowicz

E-mail: ussowicz@tlen.pl

\section{Funding sources}

This work was supported by Ligue Nationale Contre le Cancer Comité lsère (RESIST, PPE 2018) and the French SIRIC program (LYriCAN, INCa-DGOS-Inserm_12563). V.M. and J.J-D. are supported by Inserm. F.N.V.L. was a recipient of a fellowship from Ligue Nationale Contre le Cancer (LNCC) and the Fondation pour la recherche médicale (FRM).
\end{abstract}

Conflict of interest None declared

Received on February 13, 2019

Reviewed on March 7, 2019

Accepted on September 25, 2019

Published online on January 30, 2020

Cite as

Ussowicz M, Marcel V, Nguyen Van Long F, et al. Analysis of the rRNA methylation complex components in pediatric B-cell precursor acute lymphoblastic leukemia: A pilot study. Adv Clin Exp Med. 2020;29(1):107-113. doi:10.17219/acem/112608

DOI

10.17219/acem/112608

\section{Copyright}

Copyright by Author(s)

This is an article distributed under the terms of the

Creative Commons Attribution 3.0 Unported (CC BY 3.0)

(https://creativecommons.org/licenses/by/3.0/)

\begin{abstract}
Background. Dysregulation of ribosome biogenesis and alteration of ribosome composition, including alteration in ribosomal RNA (rRNA) 2'-0-ribose methylation, can play a role in malignant transformation and cancer progression. Several studies recently reported that components of the rRNA methylation complex are associated with leukemogenesis. However, no study ever investigated the alteration of ribosome biogenesis factors in the most common pediatric malignancy - B-cell precursor acute lymphoblastic leukemia (BCP-ALL).

Objectives. The objective of this study was to examine the expression of factors building the rRNA methylation complex, either the protein components (1 methyl-transferase (FBL), NOP56, NOP58, NHP2L1) or some RNA components (box C/D snoRNAs: SNORD35B, SNORD65, SNORD46, SNORD50A, SNORD38B), as well as CMYC, and nucleolin (NCL) - a protein involved in rRNA synthesis. Clinical effects in children with BCP-ALL were also investigated.
\end{abstract}

Material and methods. The factors involved in ribosome biogenesis were studied in 28 children with BCPALL with the use of real-time polymerase chain reaction (RT-PCR) using the BioMark HD System (Fluidigm, San Francisco, USA) in (DNA prepared from the bone marrow samples collected at diagnosis.

Results. Strong correlations were observed between NOP56, NOP58 and NCL, and multiple weaker correlations were observed in the box C/D snoRNA category, and between box C/D snoRNA and transcripts coding proteins of the rRNA methylation complex. The expression of analyzed transcripts did not correlate with the initial white blood cells count (WBC) or with bone marrow blast percentage. Ribosome biogenesis upregulation with overexpression of FBL and NOP56, and CMYC was found in patients who subsequently relapsed and the upregulation signature was not associated with known risk predictors.

Conclusions. This is the first report on the clinical aspect of ribosome biogenesis in pediatric BCP-ALL, and it shows that overexpression of CMYC and C/D box nucleoproteins FBL and NOP56 is an antecedent event in patients who subsequently relapse. The dysregulation pattern is different from the previous reports in acute myeloid leukemia (AML), suggesting that dysregulation of ribosome biogenesis is specific for BCP-ALL.

Key words: pediatric, methylation, relapse, acute lymphoblastic leukemia (ALL), ribosome 


\section{Introduction}

Acute lymphoblastic leukemia (ALL) is the most common malignancy in childhood with an incidence of 46.7 cases per million children under 15 years of age per year. ${ }^{1}$ The ALL is a group of various subtypes with the most common being the B-cell precursor acute lymphoblastic leukemia (BCP-ALL). Although the majority of children with ALL are cured with chemotherapy, up to $20 \%$ of patients succumb to the disease mostly due to resistant or relapsing leukemia. ${ }^{2}$ From a clinical perspective, pediatric ALL is a highly heterogeneous entity and early identification of patients with suboptimal response is necessary for therapy intensification.

Among the genes associated with leukemogenesis and clinical response in leukemia, those involved in ribosome biogenesis are promising and only now beginning to be studied. ${ }^{3-8}$ In addition, several studies reported that the high proliferation rate of tumor cells is sustained by an increased ribosome biogenesis due to hyperactivation of RNA polymerase I (RNA pol I) associated with an increase in protein synthesis. ${ }^{9}$ This view is sustained by the recent discovery that inhibiting RNA pol I activity specifically kills cancer cells in lymphoma without damaging non-cancer cells. ${ }^{10}$

Ribosomes are essential machinery in all cells, as they translate mRNA into protein. Due to their conserved sequence, their analysis was helpful in establishing evolutionary relationships between different organisms. ${ }^{11}$ Moreover, ribosomes showed a conserved structure through evolution, which is the basis of the conserved intrinsic activity of the ribosome in the tree of life. In eukaryotes, the ribosomes consist of a small subunit containing one $18 \mathrm{~S}$ ribosomal RNA (rRNA) and 33 ribosomal proteins (RPS), and a large subunit comprised of the $28 \mathrm{~S}, 5.8 \mathrm{~S}$ and $5 \mathrm{~S}$ rRNAs as well as 47 ribosomal proteins (RPL). Production of such complex ribonucleoprotein machinery takes place in the nucleolus and up to 4,500 nucleolar factors have been identified so far. ${ }^{12}$ Ribosome biogenesis requires fine regulation of rRNA synthesis using RNA pol I to give rise to a pre-rRNA, a step that is regulated by several factors, including nucleolin (NCL). A recent study reports that NCL is a marker of prognosis in acute myeloid leukemia (AML). ${ }^{5}$ The pre-rRNA is then subjected to numerous cleavages, specific folding and extensive nucleotide modifications, which are necessary to maintain the conserved ribosome structure and thus its intrinsic translational activity. ${ }^{13}$ However, recent findings showed that alterations of rRNA chemical modifications occur during tumor initiation and tumor progression, directly affecting the translation of some mRNAs coding oncogenes or tumor suppressors. ${ }^{14-18}$ Among rRNA chemical modifications, the 2'-O-ribose methylation of rRNA is the most abundant, representing more than $50 \%$ of rRNA chemical modifications. They are catalyzed by a box C/D small nucleolar ribonucleoproteins (snoRNPs) complex that contains 3 proteins involved in snoRNP structuration and assembly (NOP56, NOP58, NHP2L1), 1 methyl-transferase (FBL) and 1 box C/D small nucleolar RNA (snoRNA or SNORD), which pairs with the target RNAs determining the specific nucleotide to modification. ${ }^{18-21}$ About 250 different box C/D snoRNAs that are necessary to methylate the 106 rRNA sites at their 2'-O ribose residues have been identified. Several box C/D snoRNAs have been shown to promote leukemogenesis, including SNORD50 in T-ALL or SNORD35 in AML., ${ }^{3,6}$ Although many snoRNAs and factors involved in ribosome biogenesis have been identified to be associated with leukemogenesis or clinical outcome in different leukemia types, no study has ever investigated their alteration of expression and their clinical value in pediatric BCP-ALL. Here, we have investigated the significance of factors involved in ribosome biogenesis in the proliferative capacity and relapse propensity.

\section{Material and methods}

\section{Human samples}

The study group consisted of 28 consecutive children diagnosed with BCP-ALL treated at Department of Pediatric Hematology and Oncology (Wroclaw Medical University, Poland). The clinical characteristics of the analyzed group are presented in Table 1 . The patients were treated within the ALL IC-BFM 2009 study and according to biological and clinical factors were stratified into 3 chemotherapy arms - standard risk group (SRG), intermediate risk group (IRG) and high risk group (HRG). ${ }^{22}$ The response to the initial 7-day long therapy with glucocorticosteroids, defined

Table 1. Patient characteristics

\begin{tabular}{|c|c|c|}
\hline Category & Parameter & Value \\
\hline \multirow{2}{*}{ Sex } & male & 22 \\
\hline & female & 6 \\
\hline \multirow{2}{*}{$\begin{array}{l}\text { Age at diagnosis } \\
\text { in months }\end{array}$} & median & 40.5 \\
\hline & range & $7.3-198.1$ \\
\hline \multirow{2}{*}{$\begin{array}{l}\text { Initial peripheral blast } \\
\text { count per } \mu \mathrm{L}\end{array}$} & median & 8,456 \\
\hline & range & $0-18,7680$ \\
\hline \multirow{2}{*}{$\begin{array}{l}\text { Initial bone marrow } \\
\text { blast percentage }\end{array}$} & median & 56 \\
\hline & range & $0-95$ \\
\hline \multirow{2}{*}{ Prednisone response } & prednisone good response & 25 \\
\hline & prednisone poor response & 3 \\
\hline \multirow{3}{*}{ Risk group } & standard & 7 \\
\hline & intermediate & 16 \\
\hline & high & 5 \\
\hline \multirow{2}{*}{ Relapse } & yes & 3 \\
\hline & no & 25 \\
\hline \multirow{2}{*}{ Follow-up in months } & median & 61 \\
\hline & range & $43-84$ \\
\hline
\end{tabular}


as good (prednisone good response (PGR)) with the blast count below $1,000 / \mu \mathrm{L}$ or poor (prednisone poor response (PPR)) with blast count $\geq 1,000 / \mu \mathrm{L}$ was used as a stratification factor. During the observation period, 3 patients showed bone marrow relapse, and none of the studied patients died. The parents gave their written informed consent for the treatment and analysis of clinical data and the study was approved by the Bioethical Committee at Wroclaw Medical University.

\section{Quantification of RNA using medium throughput RT-qPCR}

Initial diagnostic bone marrow samples were collected and suspended in Trizol Reagent (Thermo Fisher Scientific, Waltham, USA) for frozen conservation. Ribonucleic acid was then purified by adding chloroform to separate nucleic acids from proteins, before it was precipitated using isopropanol and 70\% ethanol wash. Reverse transcription was performed in duplicate using the PrimeScript RT kit (Takara, Kusatsu, Japan). Briefly, 200 ng of total RNA were retrotranscribed into cDNA using a mix of 2 kind of primers: $2.5 \mathrm{M}$ oligo dT primers for mRNAs, which contain polyA at their 3'-end; and $5 \mu \mathrm{M}$ random 6 -mer primers, which allow reverse transcription of all RNAs, containing or not a poly-A, including mRNAs and snoRNAs. RNA expression levels of genes of interest were finally quantified in triplicate with real-time quantitative polymerase chain reaction (RT-qPCR) using the microfluidic mediumthroughput BioMark HD System (Fluidigm, San Francisco, USA). Utilizing the 48.48 Dynamic Array ${ }^{\mathrm{TM}}$ IFC (Fluidigm), this system allowed us to perform RT-qPCR on 48 samples by using up to 48 couples of primers. As recommended by the supplier, cDNA was subjected to an initial step of pre-amplification for 10 cycles using the PreAmp Master Mix (Fluidigm) and a mix of all the primers of interest to increase the quantity of initial cDNA matrices since each well of the 48.48 Dynamic Array ${ }^{\mathrm{TM}}$ IFC corresponds to only $6 \mathrm{~nL}$. Residues of primers were then degraded by incubation with the Exonuclease I (New England Biolabs, Ipswich, USA). Pre-amplified cDNAs were then 1:10 diluted in 1X TE buffer prior to the addition of 1X GE Sample Loading Reagent (Fluidigm) and $1 \mathrm{X}$ SsoFast ${ }^{\mathrm{TM}}$ EvaGreen $^{\circledR}$ Supermix with Low Rox (BioRad, Hercules, USA). In parallel, 2.5 M of each couple of primers was mixed with $1 \mathrm{X}$ Assay Loading Reagent (Fluidigm) and 1X DNA Suspension Buffer. After the priming of the 48.48 Dynamic Array $^{\mathrm{TM}}$ IFC in the IFC controller to prepare the microfluidic system to receive fluids, samples and assays were loaded on the chip by the IFC controller using controlled pressure, this loading method improving the technical reproducibility of the RT-qPCR. The loaded 48.48 Dynamic Array ${ }^{\mathrm{TM}}$ IFC was then introduced in the BioMark system (Fluidigm) to measure fluorescent EvaGreen at each end of PCR cycle. Raw data were analyzed using the Fluidigm Real-Time PCR Analysis software (Fluidigm).
Each couple of primers was introduced in triplicate to obtain 3 cycle thresholds (CT) values per sample. In addition to $C M Y C, 10$ genes involved in the ribosome biogenesis were quantified: the 4 genes coding proteins involved in rRNA 2'-O-ribose methylation complex ( $F B L$, NOP56, NOP58, NHP2L1); 5 C/D snoRNAs or SNORDs (SNORD35B, SNORD65, SNORD46, SNORD50A, SNOR$D 38 B)$; and 1 gene involved in rRNA synthesis $(N C L)$. Quantification of RNA was first normalized using mean of 6 housekeeping genes (ACTIN, GAPDH, HPRT1, PPIA, $P G K 1, R N U 6 B)$ then using Human XpressRef Universal Total RNA (Qiagen, Hilden, Germany) for inter- and intrarun normalization, respectively, to calculate the relative fold-change using the 2- $\Delta \Delta \mathrm{Ct}$. Expression of ribosome biogenesis factors and snoRNAs was presented as mRNA relative levels.

\section{Statistical analysis}

Statistical analysis and data presentation were performed using GraphPad Prism computer software (GraphPad Prism v. 6.07 for Windows; GraphPad Software, La Jolla, USA; www.graphpad.com). Associations between the mRNA relative levels were analyzed using Spearman's rank correlation. The Mann-Whitney U test was applied for the comparison of 2 groups, and Kruskal-Wallis test for 3 or more groups. Survival curves were estimated using the KaplanMeier method and the differences in leukemia-free survival (LFS), defined as time from diagnosis to relapse, were analyzed between subgroups using log-rank test. A p-value less than 0.05 was considered significant.

\section{Results}

The values of the mRNA relative levels were first tested for correlation with peripheral blood absolute blast count and with bone marrow blast percentage, but no statistically significant results were observed. Results are presented in Table 2. The RNA levels of all analyzed genes were analyzed and several two-by-two correlations were identified (Table 3). To determine whether correlations occur between the different gene categories (i.e., box C/D snoRNAs, proteins involved in the rRNA methylation complex or rRNA synthesis), graphical representation of correlation data was drawn (Fig. 1). Correlations were observed within the box C/D snoRNA category, and separately in the group containing the mRNA transcripts of the genes encoding the C/D box snoRNPs and NCL. The strongest correlations were observed between NOP56, NOP58 and NCL. In addition, multiple weaker correlations were observed in the box C/D snoRNA category, and between box C/D snoRNA and transcripts coding proteins of the rRNA methylation complex. For example, the SNORD35B expression correlated with NOP56/NOP58/NCL expression, while the SNORD46/SNORD38B correlated in turn with 
Table 2. Results of Spearman's rank correlation coefficient between mRNA relative levels and blast count in peripheral blood (PB) or bone marrow (BM)

\begin{tabular}{|c|c|c|c|c|c|c|c|c|c|c|c|c|}
\hline \multicolumn{2}{|c|}{ Variable } & $F B L$ & Nop56 & Nop58 & NHP2L1 & $N C L$ & CMYC & SNORD35B & SNORD65 & SNORD46 & SNORD50A & SNORD38B \\
\hline \multirow{4}{*}{$\begin{array}{c}\text { PB blast } \\
\text { count } \\
\text { vs RNA } \\
\text { levels }\end{array}$} & Spearman's $r$ & -0.34 & -0.11 & 0.067 & 0.21 & 0.27 & -0.36 & 0.14 & -0.13 & -0.081 & 0.062 & -0.073 \\
\hline & $95 \% \mathrm{Cl}$ & $\begin{array}{l}-0.64 \\
\text { to } 0.051\end{array}$ & $\begin{array}{c}-0.48 \\
\text { to } 0.28\end{array}$ & $\begin{array}{c}-0.32 \\
\text { to } 0.44\end{array}$ & $\begin{array}{c}-0.19 \\
\text { to } 0.55\end{array}$ & $\begin{array}{c}-0.12 \\
\text { to } 0.59\end{array}$ & $\begin{array}{c}-0.65 \\
\text { to } 0.027\end{array}$ & $\begin{array}{l}-0.26 \\
\text { to } 0.49\end{array}$ & $\begin{array}{c}-0.49 \\
\text { to } 0.27\end{array}$ & $\begin{array}{c}-0.45 \\
\text { to } 0.31\end{array}$ & $\begin{array}{l}-0.33 \\
\text { to } 0.43\end{array}$ & $\begin{array}{c}-0.44 \\
\text { to } 0.32\end{array}$ \\
\hline & $\begin{array}{c}\text { p-value } \\
\text { (two-tailed) }\end{array}$ & 0.0778 & 0.5673 & 0.7365 & 0.2882 & 0.1612 & 0.06 & 0.489 & 0.5057 & 0.6818 & 0.7544 & 0.7125 \\
\hline & $\begin{array}{l}\text { p-value } \\
\text { summary }\end{array}$ & ns & ns & ns & ns & ns & ns & ns & ns & ns & ns & ns \\
\hline \multirow{4}{*}{$\begin{array}{l}\text { BM blast } \\
\text { percen- } \\
\text { tage } \\
\text { vs RNA } \\
\text { levels }\end{array}$} & Spearman's r & -0.26 & -0.22 & -0.21 & 0.029 & -0.19 & -0.039 & -0.2 & 0.12 & -0.028 & -0.23 & -0.057 \\
\hline & $95 \% \mathrm{Cl}$ & $\begin{array}{l}-0.58 \\
\text { to } 0.14\end{array}$ & $\begin{array}{l}-0.56 \\
\text { to } 0.18\end{array}$ & $\begin{array}{c}-0.55 \\
\text { to } 0.19\end{array}$ & $\begin{array}{c}-0.36 \\
\text { to } 0.41\end{array}$ & $\begin{array}{l}-0.54 \\
\text { to } 0.20\end{array}$ & $\begin{array}{c}-0.42 \\
\text { to } 0.35\end{array}$ & $\begin{array}{l}-0.54 \\
\text { to } 0.19\end{array}$ & $\begin{array}{l}-0.27 \\
\text { to } 0.48\end{array}$ & $\begin{array}{c}-0.41 \\
\text { to } 0.36\end{array}$ & $\begin{array}{l}-0.56 \\
\text { to } 0.17\end{array}$ & $\begin{array}{l}-0.43 \\
\text { to } 0.33\end{array}$ \\
\hline & $\begin{array}{c}\text { p-value } \\
\text { (two-tailed) }\end{array}$ & 0.1879 & 0.2608 & 0.2817 & 0.8832 & 0.3219 & 0.8446 & 0.2965 & 0.5389 & 0.8888 & 0.2483 & 0.7715 \\
\hline & $\begin{array}{l}\text { p-value } \\
\text { summary }\end{array}$ & ns & ns & ns & ns & ns & ns & ns & ns & ns & ns & ns \\
\hline
\end{tabular}

95\% Cl - 95\% confidence interval.

Table 3. Results of Spearman's rank correlation coefficient between mRNA relative levels of the analyzed transcripts

\begin{tabular}{|c|c|c|c|c|c|c|c|c|c|c|c|}
\hline Gene & $F B L$ & NOP56 & NOP58 & NHP2L1 & $N C L$ & CMYC & SNORD35B & SNORD65 & SNORD46 & SNORD50A & SNORD38B \\
\hline$F B L$ & & $p=0.008$ & $p=0.21$ & $p=0.15$ & $p=0.4$ & $p=0.1$ & $p=0.36$ & $p=0.087$ & $p=0.23$ & $p=0.98$ & $p=0.59$ \\
\hline NOP56 & $0.49^{*}$ & & $p<0.001$ & $p=0.04$ & $p<0.001$ & $p=0.7$ & $p<0.001$ & $p=0.51$ & $p=0.25$ & $p=0.65$ & $p=0.21$ \\
\hline NOP58 & 0.24 & $0.68^{*}$ & & $p=0.02$ & $p<0.001$ & $p=0.67$ & $p<0.001$ & $p=0.86$ & $p=0.06$ & $p=0.45$ & $p=0.027$ \\
\hline NHP2L1 & 0.28 & $0.38 *$ & $0.42 *$ & & $p=0.007$ & $p=0.7$ & $p=0.29$ & $p=0.25$ & $p=0.3$ & $p=0.12$ & $p=0.42$ \\
\hline$N C L$ & 0.17 & $0.74 *$ & $0.65^{*}$ & $0.5^{*}$ & & $p=0.31$ & $p=0.002$ & $p=0.8$ & $p=0.82$ & $p=0.11$ & $p=0.88$ \\
\hline CMYC & 0.31 & 0.07 & -0.08 & -0.07 & -0.2 & & $p=0.75$ & $p=0.46$ & $p=0.88$ & $p=0.69$ & $p=0.96$ \\
\hline SNORD35B & 0.18 & $0.65^{*}$ & $0.67^{*}$ & 0.21 & $0.55^{*}$ & -0.06 & & $p=0.37$ & $p=0.02$ & $p=0.14$ & $p=0.009$ \\
\hline SNORD65 & -0.32 & -0.13 & -0.03 & -0.22 & -0.05 & -0.14 & -0.18 & & $p=0.26$ & $p=0.4$ & $p=0.38$ \\
\hline SNORD46 & 0.23 & 0.22 & 0.35 & 0.2 & -0.04 & 0.03 & $0.43^{*}$ & -0.22 & & $p=0.007$ & $p=0.012$ \\
\hline SNORD50A & 0 & -0.1 & 0.15 & -0.38 & -0.31 & -0.08 & 0.28 & -0.16 & $0.5^{*}$ & & $p<0.001$ \\
\hline SNORD38B & 0.1 & 0.24 & $0.42 *$ & -0.16 & -0.03 & -0.01 & $0.48^{*}$ & -0.17 & $0.47^{*}$ & $0.61 *$ & \\
\hline
\end{tabular}

Lower part of the table shows Spearman's rho and upper part the p-values. Statistically significant results are shown in bold and marked with an asterisk.

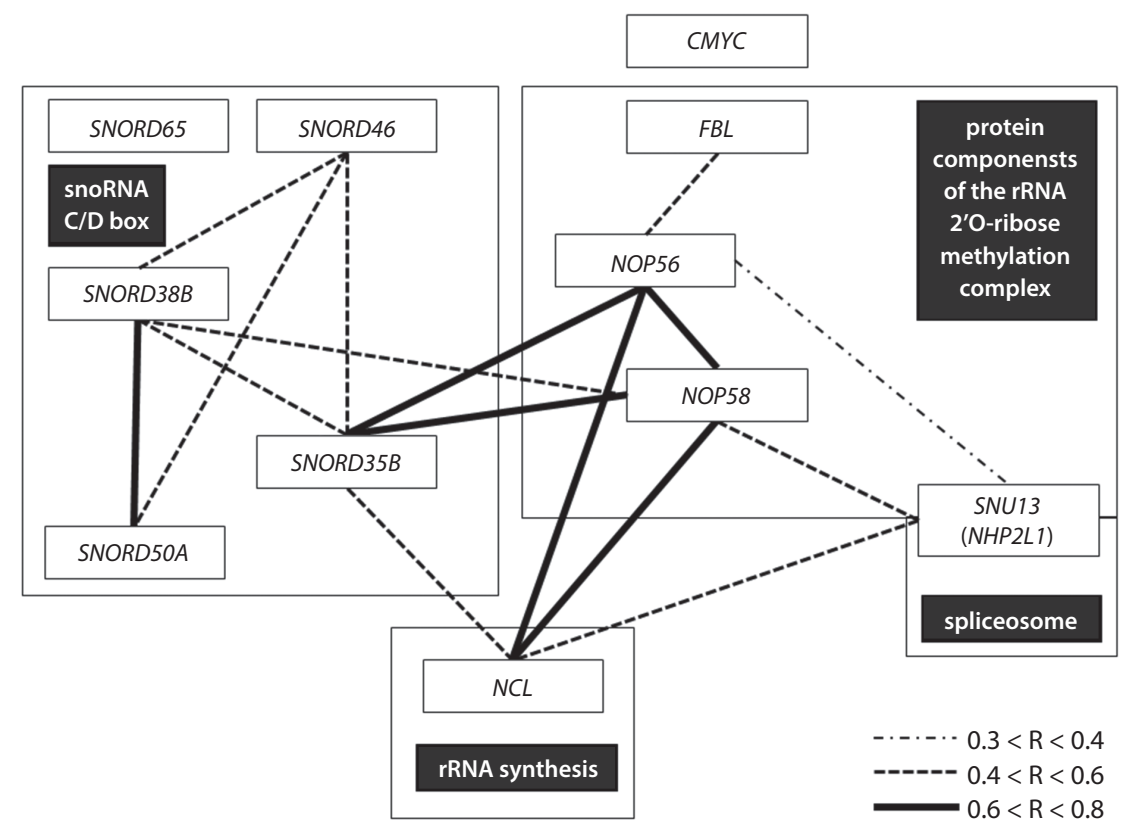

Fig. 1. The correlations between mRNA relative levels of analyzed transcripts. The lines represent the values of Spearman's rank correlation coefficient 


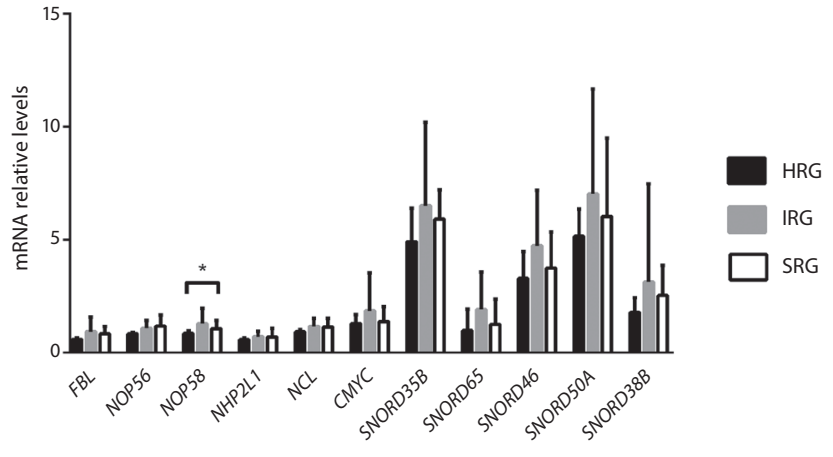

Fig. 2. The mRNA relative levels of analyzed transcripts among patients within different risk stratification groups (high risk group (HRG), intermediate risk group (IRG) and standard risk group (SRG))

Bars and whiskers on the plot represent mean and standard deviation (SD) ${ }^{*} p<0.05$.

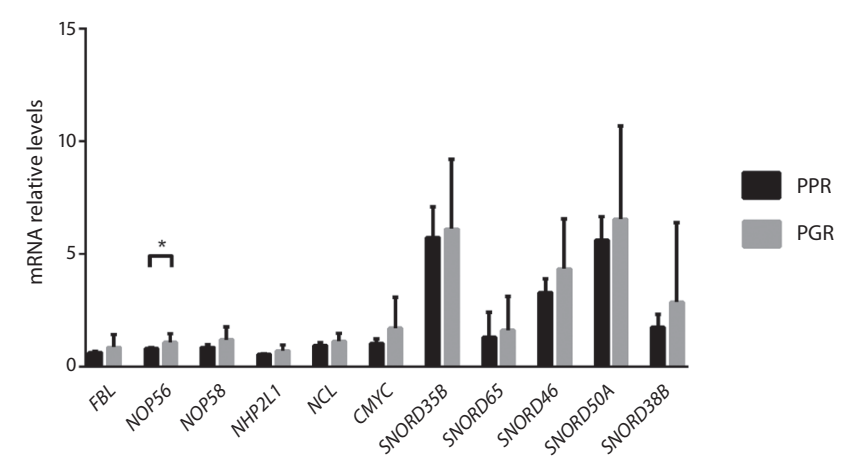

Fig. 3. The RNA relative levels in patients with prednisone good response (PGR) and prednisone poor response (PPR)

Bars and whiskers on the plot represent mean and standard deviation (SD). ${ }^{*} p<0.05$.

SNORD35B. RNA relative levels of all transcripts were analyzed for correlation with initial peripheral blast count, initial marrow blast percentage and factors used to establish the different risk stratification groups (HRG, IRG and SRG) (Fig. 2). The RNA levels of the NOP58 were associated with risk stratification $(\mathrm{p}=0.04)$. The response to the initial steroid therapy was assessed as PGR in 25 children and PPR in 3 children. The mRNA relative levels for all tested genes were compared between groups with PGR and PPR (Fig. 3). In the PGR group, only the NOP56 RNA levels were lower $(\mathrm{p}=0.03)$. During the observation period, 3 patients relapsed, all in the IRG, and all showed PGR. We then evaluated the association of expression of ribosome biogenesis factors with the later stage of the BCPALL disease. The groups of patients who either remained in complete remission (CR) or relapsed were compared for the mRNA relative levels of analyzed transcripts (Fig. 4). Initial RNA levels of $F B L, N O P 56, C M Y C$, SNORD35B, and $S N O R D 46$ were significantly higher in the patients who subsequently experienced the leukemia relapse than in those who remained in CR. For each factor identified as significant (FBL, NOP56, CMYC, SNORD35B, and $S N O R D 46)$, the patients were grouped based on the RNA

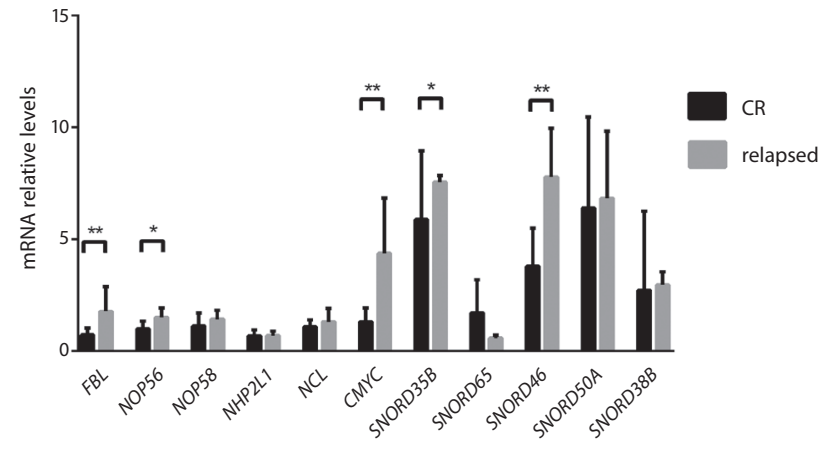

Fig. 4. The mRNA relative levels at first diagnosis of analyzed transcripts between patients who maintained complete remission (CR) and those who relapsed

Bars and whiskers on the plot represent mean and standard deviation (SD). ${ }^{*} p<0.05 ;{ }^{* *} p<0.005$.

levels $-1^{\text {st }}$ group $1-3 \mathrm{Q}$ - below the $3^{\text {rd }}$ quartile, and the $2^{\text {nd }}$ $-4 \mathrm{Q}$ - above the $3^{\text {rd }}$ quartile (Fig. 5). The survival analysis revealed inferior probability of LFS (pLFS) in the $F B L$, CMYC, SNORD35B, and SNORD46 4Q groups (1-3Q vs $4 \mathrm{Q}, 100 \%$ vs $57 \%, \mathrm{p}=0.0011$ ), and in all relapsing patients the analyzed RNA levels were above the $3^{\text {rd }}$ quartile threshold.

Overall, these data show that expression of some ribosome biogenesis factors at diagnosis might be associated with patient relapse.

\section{Discussion}

The association between ribosomal dysregulation and tumorigenesis is indisputable, as proven by increased carcinogenesis risk in constitutional diseases caused by ribosomal gene mutations. ${ }^{23}$ In T-cell acute lymphoblastic leukemia (T-ALL), the ribosome function is indeed deregulated through mutations in RPL genes, leading to impaired ribosome biogenesis and translational fidelity. ${ }^{24-26}$ Homeostasis of ribosomal machinery thus appears crucial for the preservation of steadfast protein synthesis and there are observations that during tumorigenesis, including leukemogenesis, these mechanisms are flawed.

Our research on expression of different ribosomal biogenesis factors in the analyzed BCP-ALL group showed multiple positive correlations between mRNA expression levels. The correlation of NOP56/NOP58/NCL points to common regulation mechanisms responsible for ribosome biogenesis dysregulation in leukemic cells. The upregulation of box C/D snoRNP components can be caused by the dysregulation of the intracellular genetic homeostasis enacted by upstream regulators like TP53 and CMYC, both of them reported as strong regulators of box C/D snoRNAs, and other proteins involved in the rRNA methylation complex. $6,16,27,28$

Interestingly, we observed the signature of ribosome biogenesis upregulation at initial diagnosis in BCP-ALL 
A

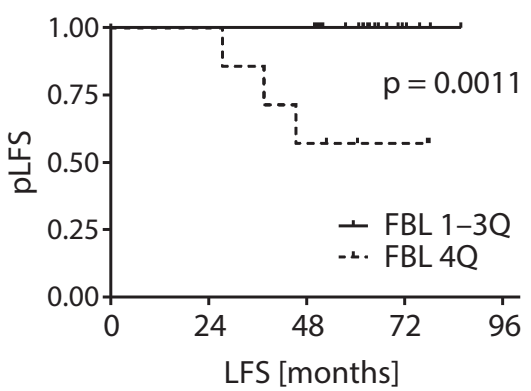

D

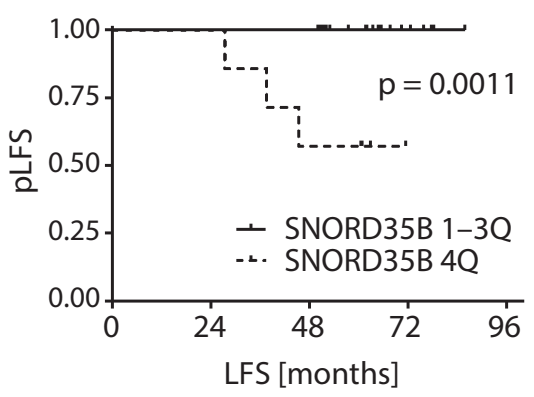

B

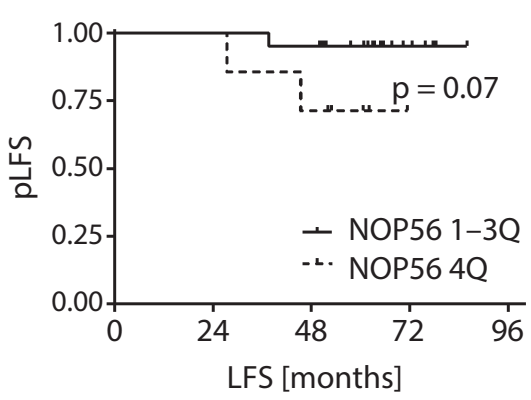

E

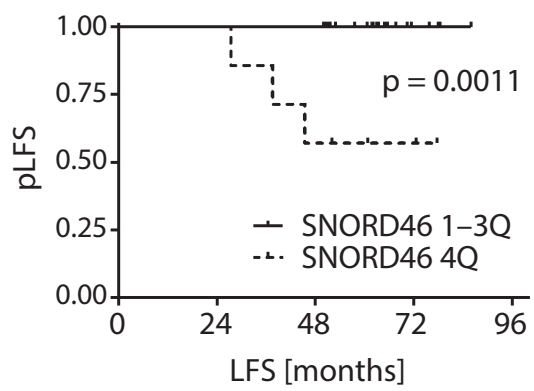

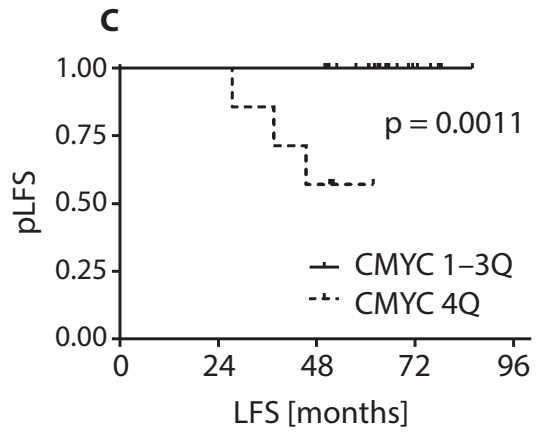

Fig. 5. The probability of leukemia-free survival (pLFS) in patients grouped according to RNA levels of $F B L(A)$, NOP56 (B), CMYC (C), SNORD35B (D), and SNORD46 (D). Groups: 1-3Q - below $3^{\text {rd }}$ RNA level quartile, $4 \mathrm{Q}$ - above the $3^{\text {rd }}$ RNA level quartile patients who subsequently relapsed. The increased expression levels of $C M Y C$ and the components of the rRNA methylation complex, such as FBL and NOP56, were identified in patients, even though leukemic clone in 3 out of 3 children did not show PPR or resistance to chemotherapy with delayed remission. The role of FBL and NOP56 proteins can be pivotal in the enhancement of ribosomal biogenesis. Animal studies showed that $F B L$ regulates stem cell pluripotency, and gene knockdown led to significant delays in rRNA processing, growth inhibition and apoptosis. ${ }^{29}$ Thus, the upregulation of $F B L$ can protect leukemic cells from self-elimination and sustains mechanism leading to further evolution. The $F B L$ was shown to be responsible for the decrease in translational quality control in response to p53 inhibition. ${ }^{16}$ The $F B L$ overexpression promoted in vitro MCF7 breast cancer cells proliferation and protected cells from doxorubicin, and was associated with poor survival in tumor patients. ${ }^{16}$ The lack of correlation of RNA expression with peripheral blast count and tumor burden suggests that the leukemic cells do not require the upregulation of protein synthesis machinery to maintain massive proliferation. The increased initial peripheral blast count in ALL is considered an unfavorable prognostic factor and is included into the stratification of therapeutic protocol with a chance of chemotherapy intensification. In the analyzed cohort, the NCL gene - direct enhancer of ribosomal production - was not overexpressed. The normal expression of NCL-1 in Caenorhabditis elegans (C. elegans) is correlated with the repression of rRNA synthesis and decreased cell, and loss of function mutations in the nucleolin gene leads to increased protein and rRNA production with increased nematodes body size. ${ }^{30}$ In AML, the mutations of NPM1 lead to loss of interaction with NCL protein contributing to leukemogenesis. ${ }^{31}$ Nucleolin was found to be overexpressed in AML blasts and a high NCL mRNA expression level was associated with poor overall survival, particularly in elderly patients. ${ }^{5}$ The prognostic role of the NCL expression was not identified in our cohort and the NCL upregulation did not identify the patients at risk of relapse, suggesting that the intensified chemotherapy in pediatric ALL can compensate for this effect.

Only the NOP56 RNA levels were significantly higher in the PPR subgroup, but NOP56 RNA level did not affect LFS. Steroid resistance in ALL is only partially elucidated by the presence of complex mechanisms related to intracellular expression of the glucocorticosteroid receptor itself, signaling pathways modulating its function and enzymes modifying the availability of its ligands. ${ }^{32-34}$ This effect emphasizes the complexity of leukemic transformation with multiple dysregulated mechanisms of cellular homeostasis.

\section{Conclusions}

This is the first report on the clinical aspect of ribosome biogenesis in pediatric BCP-ALL identifying the overexpression of the rRNA methylation complex components, FBL, NOP56, CMYC, and SNORD46 as an antecedent event in patients who subsequently relapse. The results may suggest that the analyzed ribosome biogenesis factor expression levels are not related to known initial risk predictors. Due to the low number of analyzed patients, the study lacks the power to identify all factors associated with leukemia relapse. In order to validate the presented 
findings and to determine the value of ribosomal profiling as potential new risk factors, studies in larger groups are necessary. In conclusion, the observed dysregulation pattern in BCP-ALL is different from the reports in AML, suggesting a specificity in ribosome biogenesis defects in BCP-ALL compared to other leukemias.

\section{ORCID iDs}

Marek Ussowicz (1) https://orcid.org/0000-0001-5725-4835 Virginie Marcel (1) https://orcid.org/0000-0002-9557-8221 Flora Nguyen Van Long (1) https://orcid.org/0000-0003-1147-4351 Bernarda Kazanowska (1) https://orcid.org/0000-0002-7198-9122 Jean-Jacques Diaz (1) https://orcid.org/0000-0002-7914-4319 Dariusz Wołowiec (1) https://orcid.org/0000-0003-4081-5397

\section{References}

1. WHO Europe. Incidence of childhood leukaemia. http://www.euro. who.int/_data/assets/pdf_file/0005/97016/4.1.-Incidence-of-childhood-leukaemia-EDITED_layouted.pdf.

2. Möricke A, Zimmermann M, Reiter A, et al. Long-term results of five consecutive trials in childhood acute lymphoblastic leukemia performed by the ALL-BFM study group from 1981 to 2000. Leukemia. 2010;24(2):265-284. doi:10.1038/leu.2009.257

3. Gachet $\mathrm{S}$, El-Chaar T, Avran D, et al. Deletion $6 \mathrm{q}$ drives T-cell leukemia progression by ribosome modulation. Cancer Discov. 2018;8(12): 1614-1631. doi:10.1158/2159-8290.CD-17-0831

4. Warner WA, Spencer DH, Trissal M, et al. Expression profiling of snoRNAs in normal hematopoiesis and AML. Blood Adv. 2018;2(2):151-163. doi:10.1182/bloodadvances.2017006668

5. Marcel V, Catez F, Berger CM, et al. Expression profiling of ribosome biogenesis factors reveals nucleolin as a novel potential marker to predict outcome in AML patients. PLoS One. 2017;12(1):e0170160. doi:10.1371/journal.pone. 0170160

6. Zhou F, Liu Y, Rohde C, et al. AML1-ETO requires enhanced C/D box snoRNA/RNP formation to induce self-renewal and leukaemia. Nat Cell Biol. 2017;19(7):844-855. doi:10.1038/ncb3563

7. Bellodi C, McMahon M, Contreras A, et al. H/ACA small RNA dysfunctions in disease reveal key roles for noncoding RNA modifications in hematopoietic stem cell differentiation. Cell Rep. 2013;3(5):1493-1502. doi:10.1016/j.celrep.2013.04.030

8. Valleron W, Laprevotte E, Gautier E-F, et al. Specific small nucleoIar RNA expression profiles in acute leukemia. Leukemia. 2012;26(9): 2052-2060. doi:10.1038/leu.2012.111

9. Marcel V, Catez F, Diaz J-J. Ribosomes: The future of targeted therapies? Oncotarget. 2013;4(10):1554-1555. doi:10.18632/oncotarget.1511

10. Bywater MJ, Pearson RB, McArthur GA, Hannan RD. Dysregulation of the basal RNA polymerase transcription apparatus in cancer. Nat Rev Cancer. 2013;13(5):299-314. doi:10.1038/nrc3496

11. Doolittle WF. Phylogenetic classification and the universal tree. Science. 1999;284(5423):2124-2129.

12. Ahmad Y, Boisvert F-M, Gregor P, Cobley A, Lamond Al. NOPdb: Nucleolar Proteome Database - 2008 update. Nucleic Acids Res. 2009; 37(Database issue):D181-184. doi:10.1093/nar/gkn804

13. Natchiar SK, Myasnikov AG, Kratzat H, Hazemann I, Klaholz BP. Visualization of chemical modifications in the human 805 ribosome structure. Nature. 2017;551(7681):472-477. doi:10.1038/nature24482

14. Marcel V, Catez F, Diaz J-J. Ribosome heterogeneity in tumorigenesis: The rRNA point of view. Mol Cell Oncol. 2(3):e983755. doi:10.4161 /23723556.2014.983755

15. Belin S, Beghin A, Solano-Gonzàlez E, et al. Dysregulation of ribosome biogenesis and translational capacity is associated with tumor progression of human breast cancer cells. PLoS One. 2009;4(9):e7147. doi:10.1371/journal.pone.0007147
16. Marcel V, Ghayad SE, Belin S, et al. p53 acts as a safeguard of translational control by regulating fibrillarin and rRNA methylation in cancer. Cancer Cell. 2013;24(3):318-330. doi:10.1016/j.ccr.2013.08.013

17. Erales J, Marchand V, Panthu B, et al. Evidence for rRNA 2'-O-methylation plasticity: Control of intrinsic translational capabilities of human ribosomes. Proc Natl Acad Sci U S A. 2017;114(49):12934-12939. doi:10. 1073/pnas.1707674114

18. Ruggero D, Grisendi S, Piazza F, et al. Dyskeratosis congenita and cancer in mice deficient in ribosomal RNA modification. Science. 2003:299(5604):259-262. doi:10.1126/science.1079447

19. Yip WSV, Vincent NG, Baserga SJ. Ribonucleoproteins in archaeal prerRNA processing and modification. Archaea. 2013;2013:1-14. doi:10. 1155/2013/614735

20. Balakin AG, Smith L, Fournier MJ. The RNA world of the nucleolus: Two major families of small RNAs defined by different box elements with related functions. Cell. 1996;86(5):823-834. doi:10.1016/S00928674(00)80156-7

21. Gagnon KT, Biswas S, Zhang X, et al. Structurally conserved Nop56/58 $\mathrm{N}$-terminal domain facilitates archaeal box C/D ribonucleoproteinguided methyltransferase activity. J Biol Chem. 2012;287(23):1941819428. doi:10.1074/jbc.M111.323253

22. ALL IC-BFM 2009: A randomized trial of the I-BFM-SG for the management of childhood non-B acute lymphoblastic leukemia. Kiel, Germany, August 14, 2009.

23. Nakhoul H, Ke J, Zhou X, Liao W, Zeng SX, Lu H. Ribosomopathies: Mechanisms of disease. Clin Med Insights Blood Disord. 2014;7:7-16. doi:10.4137/CMBD.S16952

24. Girardi T, De Keersmaecker K. T-ALL: All a matter of translation? Haematologica. 2015;100(3):293-295. doi:10.3324/haematol.2014.118562

25. De Keersmaecker K, Atak ZK, Li N, et al. Exome sequencing identifies mutation in CNOT3 and ribosomal genes RPL5 and RPL10 in T-cell acute lymphoblastic leukemia. Nat Genet. 2013;45(2):186-190. doi:10.1038/ng.2508

26. Sulima SO, Patchett S, Advani VM, De Keersmaecker K, Johnson AW, Dinman JD. Bypass of the pre-60S ribosomal quality control as a pathway to oncogenesis. Proc Nat IAcad SciU S A. 2014;111(15):5640-5645. doi:10.1073/pnas.1400247111

27. Krastev DB, Slabicki M, Paszkowski-Rogacz M, et al. A systematic RNAi synthetic interaction screen reveals a link between $\mathrm{p} 53$ and snoRNP assembly. Nat Cell Biol. 2011;13(7):809-818. doi:10.1038/ncb2264

28. Coller HA, Grandori C, Tamayo P, et al. Expression analysis with oligonucleotide microarrays reveals that MYC regulates genes involved in growth, cell cycle, signaling, and adhesion. Proc Natl Acad SciU SA. 2000;97(7):3260-3265. doi:10.1073/pnas.97.7.3260

29. Watanabe-Susaki K, Takada H, Enomoto K, et al. Biosynthesis of ribosomal RNA in nucleoli regulates pluripotency and differentiation ability of pluripotent stem cells. Stem Cells. 2014;32(12):3099-3111. doi:10.1002/stem.1825

30. Frank DJ, Roth MB. ncl-1 is required for the regulation of cell size and ribosomal RNA synthesis in Caenorhabditis elegans. J Cell Biol. 1998;140(6):1321-1329. doi:10.1083/jcb.140.6.1321

31. Šašinková $M$, Holoubek A, Otevřelová P, Kuželová K, Brodská B. AMLassociated mutation of nucleophosmin compromises its interaction with nucleolin. Int J Biochem Cell Biol. 2018;103:65-73. doi:10.1016/j. biocel.2018.08.008

32. Kruth KA, Fang M, Shelton DN, et al. Suppression of B-cell development genes is key to glucocorticoid efficacy in treatment of acute lymphoblastic leukemia. Blood. 2017;129(22):3000-3008. doi:10.1182/ blood-2017-02-766204

33. Kelekar A, Thompson CB. BCl-2-family proteins: The role of the BH3 domain in apoptosis. Trends Cell Biol. 1998;8(8):324-330. doi:10.1016/ S0962-8924(98)01321-X

34. Sai S, Nakagawa Y, Sakaguchi K, et al. Differential regulation of $11 \beta$-hydroxysteroid dehydrogenase- 1 by dexamethasone in glucocorticoid-sensitive and -resistant childhood lymphoblastic leukemia. Leuk Res. 2009;33(12):1696-1698. doi:10.1016/j.leukres.2009.04.016 